\title{
A Computer Generated Reduced Iso-Octane Chemical Kinetic Mechanism Applied to Simulation of $\mathrm{HCCl}$ Combustion
}

S.M. Aceves, J. Martinez-Frias, D. Flowers, J.R. Smith R. Dibble, J.Y. Chen

U.S. Department of Energy

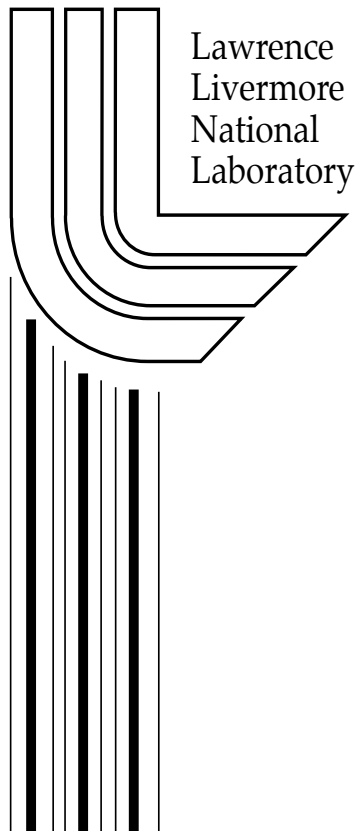

This article was submitted to Society of Automotive Engineers

Powertrain \& Fluid Systems, San Diego, CA, October 21-24, 2002

August 12, 2002 


\section{DISCLAIMER}

This document was prepared as an account of work sponsored by an agency of the United States Government. Neither the United States Government nor the University of California nor any of their employees, makes any warranty, express or implied, or assumes any legal liability or responsibility for the accuracy, completeness, or usefulness of any information, apparatus, product, or process disclosed, or represents that its use would not infringe privately owned rights. Reference herein to any specific commercial product, process, or service by trade name, trademark, manufacturer, or otherwise, does not necessarily constitute or imply its endorsement, recommendation, or favoring by the United States Government or the University of California. The views and opinions of authors expressed herein do not necessarily state or reflect those of the United States Government or the University of California, and shall not be used for advertising or product endorsement purposes.

This is a preprint of a paper intended for publication in a journal or proceedings. Since changes may be made before publication, this preprint is made available with the understanding that it will not be cited or reproduced without the permission of the author.

This report has been reproduced directly from the best available copy.

Available electronically at http://www.doc.gov/bridge

Available for a processing fee to U.S. Department of Energy

And its contractors in paper from

U.S. Department of Energy

Office of Scientific and Technical Information

P.O. Box 62

Oak Ridge, TN 37831-0062

Telephone: (865) 576-8401

Facsimile: (865) 576-5728

E-mail: reports@adonis.osti.gov

Available for the sale to the public from

U.S. Department of Commerce

National Technical Information Service

5285 Port Royal Road

Springfield, VA 22161

Telephone: (800) 553-6847

Facsimile: (703) 605-6900

E-mail: orders@ntis.fedworld.gov

Online ordering: http://www.ntis.gov/ordering.htm

\section{OR}

Lawrence Livermore National Laboratory

Technical Information Department's Digital Library

http:/ / www.llnl.gov/tid / Library.html 


\title{
A Computer Generated Reduced Iso-Octane Chemical Kinetic Mechanism Applied to Simulation of $\mathrm{HCCl}$ Combustion
}

\author{
Salvador M. Aceves, Joel Martinez-Frias, Daniel Flowers, J. Ray Smith \\ Lawrence Livermore National Laboratory \\ Robert Dibble, J.Y. Chen \\ University of California Berkeley
}

Copyright (C) 2001 Society of Automotive Engineers, Inc.

\begin{abstract}
This paper shows how a computer can systematically remove non-essential chemical reactions from a large chemical kinetic mechanism. The computer removes the reactions based upon a single solution using a detailed mechanism. The resulting reduced chemical mechanism produces similar numerical predictions significantly faster than predictions that use the detailed mechanism.
\end{abstract}

Specifically, a reduced chemical kinetics mechanism for iso-octane has been derived from a detailed mechanism by eliminating unimportant reaction steps and species. The reduced mechanism has been developed for the specific purpose of fast and accurate prediction of ignition timing in an $\mathrm{HCCl}$ engine. The reduced mechanism contains 199 species and 383 reactions, while the detailed mechanism contains 859 species and 3606 reactions. Both mechanisms have been used in numerical simulation of $\mathrm{HCCl}$ combustion. The simulations show that the reduced mechanism predicts pressure traces and heat release with good accuracy, similar to the accuracy obtained with the detailed mechanism.

As may be expected, emissions of hydrocarbon and carbon monoxide are not as well predicted with the reduced mechanism as with the detailed mechanism, since the reduced mechanism was targeted for predicting $\mathrm{HCCl}$ ignition and not $\mathrm{HC}$ and $\mathrm{CO}$ emissions. Considering that the reduced mechanism requires about 25 times less computational time than the detailed mechanism ( 2 hours vs. 2 days), the ability to automatically generate a problem specific reduced mechanism is an important new tool for combustion research in general.

\section{INTRODUCTION}

It is generally believed that a complete chemical mechanism, combined with the Navier Stokes equations will lead to numerical simulations of all combustion phenomena. This includes flame speeds as a function of temperature, pressure and stoichiometry; chemiluminescence from flames; explosion limits: pollutant formation in flames; flammability limits at all temperatures and pressures; and all other features. In practice, a numerical simulation that carries complete physics will likely tax the speed of any computer; this is certainly true if the flow is turbulent. Such a complete description is seldom attempted. Out of necessity, one makes judicious assumptions that reduce the dimensionality of the problem, in both fluid dynamic space and-or in chemical kinetic space, until a tractable problem is achieved. A reduction in dimensionality of chemical kinetic space means removal of "unimportant" species. This reduction is done at some loss in fidelity, yet, chemical kinetic mechanisms can be judiciously "reduced." Such reduced mechanisms can reduce the computational time while retaining key important features and losing features that are deemed unimportant. Thus, autoignition chemistry can be retained while other details, such as soot production chemistry, for example, may not be retained in the "simplified" ignition mechanism.

In the past, a reduced chemical kinetic mechanism was the result of trial and error. Recent developments in understanding chemical kinetics by computer methods, such as Computational Singular Perturbation (CSP) [1] and Intrinsic Low Dimensional Manifold (ILDM) [2], allow systematic identification unimportant species and reaction steps. Reviews on methods for mechanism reduction and on reduced chemistry have been provided by Frenchlack [3] and Griffiths [4]. Specific applications to $\mathrm{HCCl}$ chemical kinetics using automatic approaches have been illustrated recently for natural gas combustion $[5,6]$. This paper reports the development of a reduced chemical kinetic mechanism for oxidation of iso-octane from a large mechanism using a computer with an automatic procedure. We then insert the reduced mechanism, of iso-octane oxidation, into a numerical simulation of $\mathrm{HCCl}$ combustion. 
The need for a reduced mechanism is illustrated by a brief review of our previous work on simulation of $\mathrm{HCCl}$ engines. We have combined detailed chemical kinetics with fluid mechanics for high fidelity predictions of combustion in $\mathrm{HCCl}$ engines. These early successes were done with relatively simple fuels (methane, propane) that have relatively small detailed chemical kinetic mechanisms. With these simple fuels, computational times were about 2 hours, and we had little need for reduced mechanisms. As we evolved to simulations of $\mathrm{HCCl}$ using more complicated fuels, our numerical predictions were taking more and more computational time; the run time increasing as the square of the number of species. These longcomputational-time simulations, using the detailed chemical mechanisms, predict many parameters well, such as ignition timing, pressure trace, and emissions of pollutants. However, such long computational times are impractical for surveys and optimization studies. We will show that much faster computations can be achieved by focusing on, for example, ignition timing alone. It is possible to remove from the detailed mechanism reactions and species that do not significantly contribute to the chemistry that leads up to the ignition event. The automatic procedure for simplifying the detailed mechanism is presented below, after a discussion of the numerical model of $\mathrm{HCCl}$ combustion.

\section{HCCI ANALYSIS WITH SEQUENTIAL FLUID DYNAMICS AND CHEMISTRY}

Homogeneous Charge Compression Ignition ( $\mathrm{HCCl}$ ) engines are being considered as a future alternative for diesel engines. $\mathrm{HCCl}$ engines have the potential for high efficiency (diesel-like [7]), very low nitrogen oxide (NOx) and particulate matter emissions, and low cost (because no high-pressure injection system is required). Disadvantages of $\mathrm{HCCl}$ engines are high hydrocarbon (HC) and carbon monoxide (CO) emissions, high peak pressures, high rates of heat release, reduced engine speed range, reduced power per displacement, and difficulty in starting and controlling the engine.

It is generally accepted that $\mathrm{HCCl}$ combustion is dominated by chemical kinetics [8], with no requirement for flame propagation. This notion has been supported by spectroscopy experiments, which indicate that the order of radical formation in $\mathrm{HCCl}$ combustion corresponds to self-ignition instead of flame propagation $[9,10]$. If a truly homogeneous mixture exists at the time of combustion, turbulence has little direct effect on $\mathrm{HCCl}$ combustion, but it may have an indirect effect by altering the temperature distribution and the boundary layer thickness within the cylinder. Small temperature differences inside the cylinder have a considerable effect on combustion because chemical kinetics is very sensitive to temperature.

Turbulence introduces great complexity to the analysis of spark-ignited and compression-ignited engines. The fact that $\mathrm{HCCl}$ combustion is not very sensitive to turbulence opens the possibility of developing a thorough, accurate method of simulation of $\mathrm{HCCl}$ combustion. In principle, a comprehensive model of engine combustion would be obtained by combining a computational fluid dynamics (CFD) code and a detailed chemical kinetics code. In this approach, the CFD code would calculate the temperature and composition distribution within the cylinder while simultaneously the chemical kinetics code would calculate chemical heat release as a function of pressure, temperature and composition; in each cell. The simultaneous calculation of a detailed fluid mechanics code with a detailed chemical kinetics code is well beyond our current computational capabilities. Considering that even a two-dimensional spatial grid requires thousands of CFD elements to obtain a good definition of the boundary layer and crevices, solving the simultaneous fluid flow with chemical kinetics problem would imply having to solve for thousands of well-stirred reactors, interacting with one another through heat transfer, diffusion, convection, and compression work. This is an intractable task for current computers, even when the simplest fuels (e.g., hydrogen, methanol) are considered.

Instead of attempting the overwhelmingly long task of simultaneous numerical solution of fluid mechanics and chemical kinetics, we have developed an alternative, sequential procedure for simulation of $\mathrm{HCCl}$ combustion [11-13]. The procedure uses a two-step approach. First, a fluid mechanics code (KIVA3V [14]) is used to calculate temperature histories during the compression stroke. The engine geometry-specific information calculated by KIVA3V is then handed off to a detailed chemical kinetics code (HCT; Hydrodynamics, Chemistry and Transport [15]). HCT models the combustion chamber as several fixed mass reactors (called zones) that have temperatures as determined from the KIVA3V code.

We have found that a small number of HCT zones (10) is enough to obtain accurate results; this is the big advantage of this sequential KIVA3V-HCT procedure. This procedure achieves the benefits of linking the fluid mechanics (KIVA3V) and the chemical kinetics (HCT) with a great reduction in the computational effort. Thus, an $\mathrm{HCCl}$ simulation can be handled with current computers. The methodology also shows promise for generating quantitative predictions for $\mathrm{HC}$ and $\mathrm{CO}$ emissions, and it is capable of predicting where in the cylinder the different pollutants are being generated. In addition to this, this method offers insight into the detailed chemical kinetics of the $\mathrm{HCCl}$ combustion process.

The advantages of the sequential KIVA3V-HCT procedure compared to simultaneous computations are qualitatively illustrated by Figures 1 and 2. Figure 1 shows that current computers can solve the problem of detailed fluid mechanics with very simplified chemistry, or the problem of detailed chemical kinetics with very simplified fluid mechanics. The problem of detailed fluid mechanics linked with detailed chemistry is well beyond the capabilities of even the fastest computers, making it impossible to obtain accurate predictions for spark- 
ignited and diesel engines. However, for $\mathrm{HCCl}$ combustion, the fluid mechanics and the chemistry are very much uncoupled. It is therefore possible to obtain a solution to the detailed fluid mechanics problem and a solution to the detailed chemical kinetics problem. These solutions can then be combined to obtain a solution for $\mathrm{HCCl}$ combustion that is much closer to the solution of the real problem than could otherwise be achieved with current computers (Figure 2).

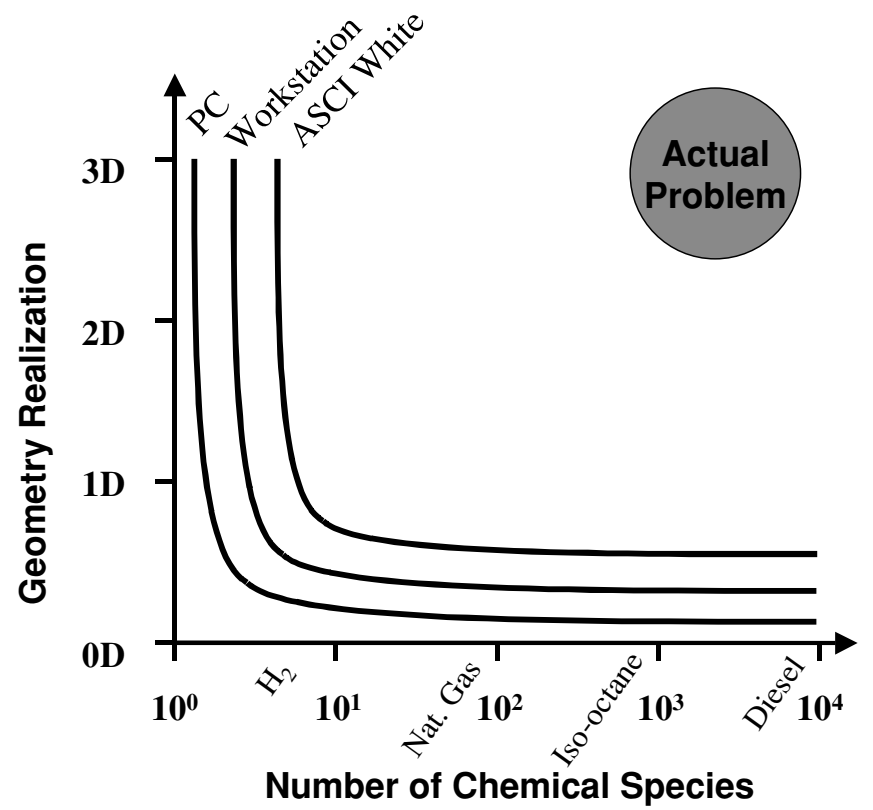

Figure 1. Qualitative representation of the capabilities of current computers, including a PC, a workstation and the fastest DOE (US Department of Energy) computer (ASCl White).

The sequential KIVA3V-HCT methodology has been successfully applied to $\mathrm{HCCl}$ engines running on natural gas [11], propane [12] and iso-octane [13]. While the procedure has general applicability to any fuel, computational time grows quickly as the number of zones and the number of species in the chemical kinetic mechanism is increased. Computational time is linearly proportional to the number of zones and proportional to the square of the number of species [13]. The running time for a 10-zone problem with propane is about 2 hours, and for the full iso-octane mechanism it is of the order of 2 days. Thus, even with the computational time savings of the sequential KIVA3V-HCT methodology for $\mathrm{HCCl}$ simulation, the computational time is far too long to practically perform sensitivity and optimization studies. It is clearly desirable to reduce the running time.

\section{REDUCED CHEMICAL MECHANISM AUTOMATICALLY GENERATED BY COMPUTER}

The reduced mechanism is developed from the detailed mechanism by eliminating unimportant reaction steps and species. We can not tell in advance what reactions and species are unimportant. We first solve the problem, or a closely related problem, using the detailed chemical kinetic mechanism to create a single "detailed solution." From examination of the "detailed solution," we can, in retrospect, decide which reactions and species may be removed. In the case of $\mathrm{HCCl}$ ignition, we find that an adequate "detailed solution" is generated by simply modeling $\mathrm{HCCl}$ as a single zone; i.e. as a well-stirred reactor with a compression and expansion stroke; we stop the computation upon ignition. It is from this "detailed solution" that we generate the reduced mechanism.

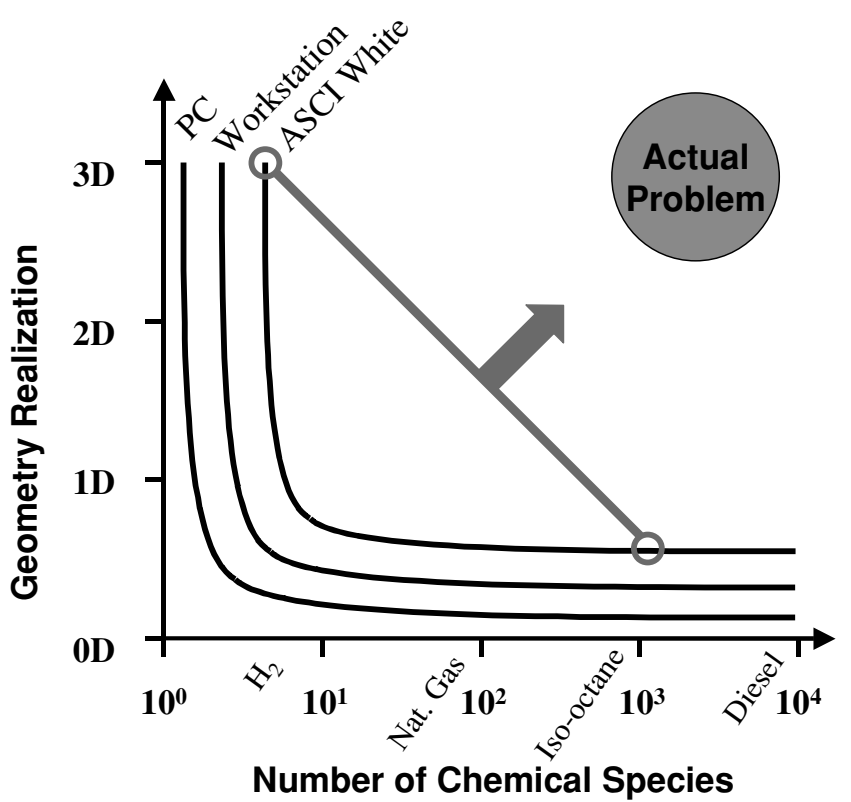

Figure 2. Qualitative representation of the capabilities of current computers, including a $\mathrm{PC}$, a workstation and the fastest DOE computer (ASCl White). For $\mathrm{HCCl}$ combustion it is possible to obtain solutions to a detailed fluid mechanics problem and to a detailed chemical kinetics problem, and combine them to obtain a solution that is very close to the solution to the real problem.

The strategy for identifying the unimportant reaction steps is to examine their normalized first-order sensitivity coefficients defined in the customary way from the reaction rates; in practice, it suffices to use the A-factor alone:

$$
\left(\frac{\partial \ln X_{k}}{\partial \ln \alpha_{i}}\right) / \max _{i}\left|\frac{\partial \ln X_{k}}{\partial \ln \alpha_{i}}\right| \operatorname{or}\left(\frac{\partial \ln T}{\partial \ln \alpha_{i}}\right) / \max _{i}\left|\frac{\partial \ln T}{\partial \ln \alpha_{i}}\right|,
$$

where $\alpha_{i}$ is the "A-factor" in the Arrhenius expression for the forward rate constant, $k_{f}=\alpha T^{\beta} \exp \left(\frac{-E_{A}}{R T}\right)$, 
and $X_{k}$ is the mole fraction of the $\mathrm{k}$-th species. A reduced mechanism consists of only those reaction steps having normalized sensitivity coefficients greater than a certain level, e.g., usually a $5 \%$ cut-off level.

In addition we examine the normalized production or destruction rates and their definitions are given as:

Normalized production value

$\overline{\mathrm{C}}_{\mathrm{ki}}^{\mathrm{p}}=\frac{\max \left(\mathrm{v}_{\mathrm{ki}}, 0\right) \mathrm{q}_{\mathrm{i}}}{\sum_{\mathrm{i}=1}^{\mathrm{I}} \max \left(\mathrm{v}_{\mathrm{ki}}, 0\right) \mathrm{q}_{\mathrm{i}}}$

Normalized destruction value

$$
\overline{\mathrm{C}}_{\mathrm{ki}}^{\mathrm{d}}=\frac{\min \left(\mathrm{v}_{\mathrm{ki}}, 0\right) \mathrm{q}_{\mathrm{i}}}{\sum_{\mathrm{i}=1}^{\mathrm{I}} \min \left(\mathrm{v}_{\mathrm{ki}}, 0\right) \mathrm{q}_{\mathrm{i}}}
$$

where $v_{k i}$ is the stoichiometric coefficient of $\mathrm{k}$-th species in i-th reaction, $q_{i}$ is the rate of reaction progress variable for the $i$-th reaction step, and $I$ is the total number of reaction steps. It is possible that the firstorder sensitivity coefficient of a species with respect to a certain reaction step is small although the corresponding normalized production or destruction value of that species is large. This particular reaction step would be eliminated by using the sensitivity analysis only; but in fact must be included into the reduced mechanism.

Based on the above considerations, a procedure has been established to construct the reduced mechanism:

We initially include those species with concentrations greater than a preset threshold, say $1 . \times 10^{-5}$ mole fraction (this is 10 parts per million (ppm)). Additional species may be picked up in step (4) and the final reduced mechanism is not sensitive to the threshold choice [16].

For each species, select reaction rates with sensitivity coefficients $\left(\frac{\partial \ln X_{k}}{\partial \ln \alpha_{i}}\right) / \max _{i}\left|\frac{\partial \ln X_{k}}{\partial \ln \alpha_{i}}\right|$ larger than a certain level, e.g., usually a $5 \%$ cut-off level. This set of reaction rates forms the first iteration to the reduced mechanism.

There may be reactions remaining in the detailed mechanism that contribute significantly to production (or destruction) of a species that is in the reduced mechanism. If so, we must add these reactions to the reduced mechanism. Thus, we examine the reaction steps that are not in the reduced mechanism to see if values of $\bar{C}_{k i}^{p}$ or $\bar{C}_{k i}^{d}$ for the species, that are in the reduced mechanism, are larger than a certain threshold, e.g., usually a $5 \%$. If so, those reactions will be added to the preliminary set.

Now that we have added more reactions to the reduced mechanism, we check if we have also added new species, from the detailed mechanism to the reduced mechanism. If yes, we then go to step (2) above and iterate again. In practice no more than 10 iterations have been needed.

In theory, a reduced mechanism should be generated from each time step of the detailed solution; fortunately, in practice, a satisfactory reduced mechanism can be generated from several judiciously chosen time steps.

We used the above algorithm to generate a reduced mechanism for application to $\mathrm{HCCl}$ engines running under wide ranges of conditions. These are listed in Table 1. The resulting reduced mechanism contains 199 species and 383 reactions, while the original detailed mechanism [17] contains 859 species and 3606 reactions. We note in passing, that these matrices $\bar{C}_{k i}^{p}$ or $\bar{C}_{k i}^{d}$ are uncommonly large, being the dimension of 859 times 3606; (roughly 50 megabytes of double precision).

Table 1. List of conditions for generation of the reduced mechanism.

\begin{tabular}{|l|c|c|}
\hline \multicolumn{1}{|c|}{ Parameter } & $\begin{array}{c}\text { Minimum } \\
\text { value }\end{array}$ & $\begin{array}{c}\text { Maximum } \\
\text { value }\end{array}$ \\
\hline Pressure & $1 \mathrm{bar}$ & $3 \mathrm{bar}$ \\
\hline Temperature & $353 \mathrm{~K}$ & $423 \mathrm{~K}$ \\
\hline $\begin{array}{l}\text { Residual gas } \\
\text { fraction }\end{array}$ & 0 & 0.7 \\
\hline Equivalence ratio & 0.2 & 0.6 \\
\hline Compression ratio & 10 & 18 \\
\hline
\end{tabular}

The applicability of a reduced mechanism is increasingly suspect when the reduced mechanism is used to solve a problem that is increasingly outside the bounds of the problem that was used for the reduction.

\section{RESULTS}

The detailed mechanism and the reduced mechanism have been applied to analyze two cases of $\mathrm{HCCl}$ combustion of iso-octane. The experiments were conducted on a Cummins $C$ engine with a bowl-in-piston geometry. The characteristics of the engine are listed in 
Table 2, and the operating conditions for the two cases being analyzed are listed in Table 3 . The analysis methodology is described in detail in previous publications [11-13].

Table 2. Main characteristics of the Cummins $\mathrm{C}$ single cylinder engine used for the $\mathrm{HCCl}$ experiments.

\begin{tabular}{|l|l|}
\hline Displaced volume & $1378 \mathrm{~cm}^{3}$ \\
\hline Bore & $114 \mathrm{~mm}$ \\
\hline Stroke & $135 \mathrm{~mm}$ \\
\hline Connecting rod length & $216 \mathrm{~mm}$ \\
\hline $\begin{array}{l}\text { Geometric compression } \\
\text { ratio }\end{array}$ & $10.5: 1$ \\
\hline Exhaust valve open & $135^{\circ}$ ATDC \\
\hline Exhaust valve close & $370^{\circ}$ ATDC \\
\hline Intake valve open & $350^{\circ}$ ATDC \\
\hline Intake valve close & $574^{\circ}$ ATDC \\
\hline Geometry & $\begin{array}{l}\text { Cylindrical bowl- } \\
\text { in-piston }\end{array}$ \\
\hline
\end{tabular}

Table 3. Main $\mathrm{HCCl}$ combustion characteristics of the two cases selected for analysis.

\begin{tabular}{|l|l|l|}
\hline & Case 1 & Case 2 \\
\hline Engine speed, rpm & 1010 & 2007 \\
\hline Intake temperature, K & 381 & 413 \\
\hline $\begin{array}{l}\text { Absolute intake } \\
\text { pressure, bar }\end{array}$ & 2.41 & 3.11 \\
\hline Equivalence ratio & 0.346 & 0.348 \\
\hline Swirl ratio & 3.6 & 3.6 \\
\hline $\begin{array}{l}\text { Peak cylinder pressure, } \\
\text { bar }\end{array}$ & 109.3 & 112.4 \\
\hline $\begin{array}{l}\text { CAD for peak heat } \\
\text { release }\end{array}$ & 0.5 ATDC & 7.0 ATDC \\
\hline burn duration, CAD & 6.3 & 9.6 \\
\hline $\begin{array}{l}\text { Combustion efficiency, } \\
\%\end{array}$ & 96.1 & 96.1 \\
\hline Gross IMEP, bar & 9.4 & 10.7 \\
\hline $\begin{array}{l}\text { Coefficient of variation } \\
\text { in gross IMEP, \% }\end{array}$ & 2.3 & 3.2 \\
\hline $\begin{array}{l}\text { Gross indicated } \\
\text { efficiency, \% }\end{array}$ & 40.5 & 43.4 \\
\hline HC emissions, g/kg fuel & 34.2 & 32.0 \\
\hline CO emissions, g/kg fuel & 21.7 & 31.5 \\
\hline $\begin{array}{l}\text { NO } \\
\text { fuel emissions, g/kg }\end{array}$ & 0.228 & 0.228 \\
\hline NO ${ }_{x}$ emissions, ppm & 5.25 & 5.28 \\
\hline
\end{tabular}

1. Burn duration is defined as the crank angle between the two points at which apparent heat release is $10 \%$ of the peak heat release.

Figure 3 shows a comparison between experimental pressure traces and numerical pressure traces for the two cases being considered. Two numerical pressure traces are included for each experimental pressure trace, corresponding to the detailed chemical kinetic mechanism and the reduced mechanism. Figure 3 shows an excellent agreement between experimental and numerical pressure traces for Cases 1 and 2. The agreement holds during the compression stroke as well as during the expansion stroke. Figure 3 shows that both the reduced and the detailed mechanisms yield results that follow very closely the experimental results.

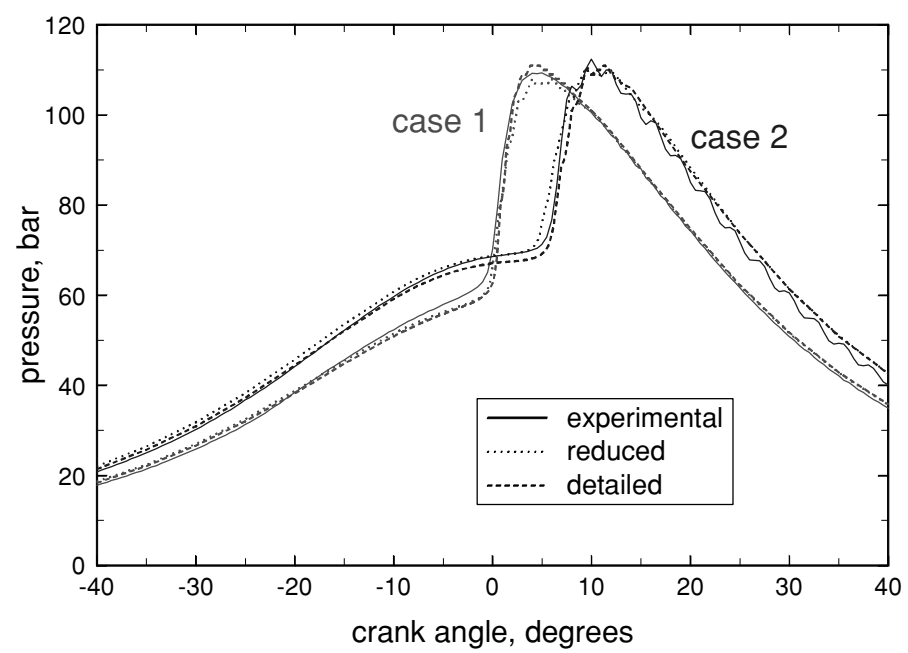

Figure 3. Comparison between experimental pressure traces and numerical pressure traces for the two cases being considered. Two numerical pressure traces are included for each experimental pressure trace, corresponding to the detailed chemical kinetic mechanism and the reduced mechanism.

Figure 4 shows a comparison between experimental and numerical apparent heat release rates. Once again, the figure shows two numerical heat release rates for each experimental heat release rate, corresponding to the detailed and the reduced chemical kinetic mechanisms. The figure shows that the reduced mechanism produces better predictions for heat release rates than the detailed mechanism. The reduced mechanism predicts very well the peak heat release as well as the width of the experimental heat release, especially for Case 2. The detailed mechanism tends to overpredict the maximum heat release rates, especially for Case 1. This better agreement by the reduced chemistry is fortuitous as the performance of reduced chemistry at best matches those of detailed chemistry. The numerical results presented in Figure 4 are considered to be in excellent agreement with the experimental results. Heat release rate is typically difficult to match numerically because heat release rate is obtained by analyzing the derivative of the pressure traces (data) applying to the first law of thermodynamics [18]. Small inaccuracies (noise) in pressure data are amplified by the derivative and can therefore result in great differences in apparent heat release rates.

Figure 5 shows a comparison between experimental and numerical results for the main combustion parameters of $\mathrm{HCCl}$, for the two cases being analyzed. Again, the 
figure shows two numerical results for each experimental result, corresponding to the reduced and the detailed chemical kinetic mechanisms. The figure shows that the results for peak cylinder pressure, indicated efficiency and combustion efficiency match very closely the experimental results (listed in Table 3). The maximum difference for these parameters is $3 \%$ for the combustion efficiency, and the average error is significantly lower than that $(1 \%)$. Burn duration (defined as the crank angle between the two points at which apparent heat release is $10 \%$ of the peak heat release) is underpredicted by about $10 \%$ for the detailed mechanism. The reduced mechanism can predict the burn duration with better accuracy.

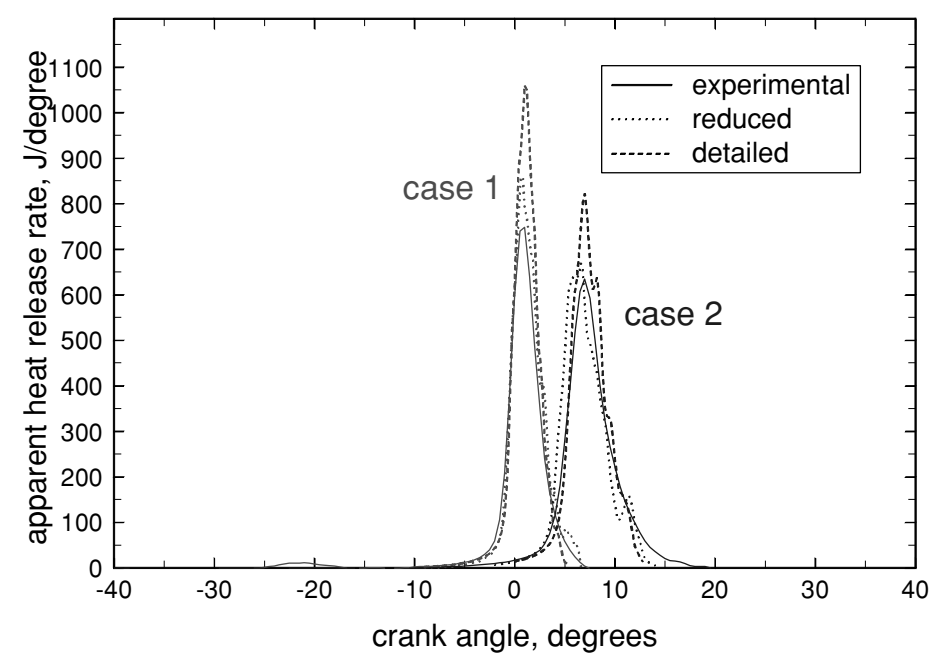

Figure 4. Comparison between experimental and numerical apparent heat release rates. The figure shows two numerical heat release rates for each experimental heat release rate, corresponding to the detailed and the reduced chemical kinetic mechanisms.

Not surprisingly, the detailed mechanism predicts hydrocarbon and carbon monoxide emissions better than the reduced mechanism. The reduced mechanism overpredicts hydrocarbon emissions by a factor of 1.35 in Case 1 and by a factor of 2 in Case 2. The detailed mechanism predicts $75 \%$ and $130 \%$ of the experimental hydrocarbon emissions respectively for Cases 1 and 2 . $\mathrm{CO}$ emissions are greatly underestimated in all cases. The detailed mechanism predicts about $10 \%$ of the experimental $\mathrm{CO}$ emissions. The reduced mechanism predicts almost 2 orders of magnitude less $\mathrm{CO}$ than measured experimentally. This is due to the fact that the reduced mechanism was targeted to predict $\mathrm{HCCl}$ ignition and not to predict $\mathrm{CO}$ emissions. In addition to this, CO emissions are intrinsically difficult to predict. During combustion, $\mathrm{CO}$ is an intermediate combustion product. Fuel is first converted into intermediate hydrocarbons, which then react to form $\mathrm{CO}$. Carbon monoxide finally reacts with $\mathrm{OH}$ to generate $\mathrm{CO} 2$ after all the hydrocarbons are consumed $(\mathrm{OH}$ reacts with hydrocarbons much faster than with $\mathrm{CO}$ ). Resolution also plays an important role in predicting $\mathrm{CO}$ emissions. Ten zones are typically not enough to accurately resolve the field to yield precise $\mathrm{CO}$ emission predictions [19]. $\mathrm{CO}$ emissions originate within a very narrow temperature range. Typically 40 zones are necessary to make sure that this narrow temperature range is properly resolved. As the chemistry for $\mathrm{CO}$ in the low-temperature crevices is different from those controlling ignition, a different reduced chemistry may be necessary for better predictions of $\mathrm{CO}$ and hydrocarbon emissions. One possibility is to run a well-mixed reactor for a misfire case and use it for developing a reduced chemistry for partial oxidation of isooctane into $\mathrm{CO}$ and hydrocarbons.

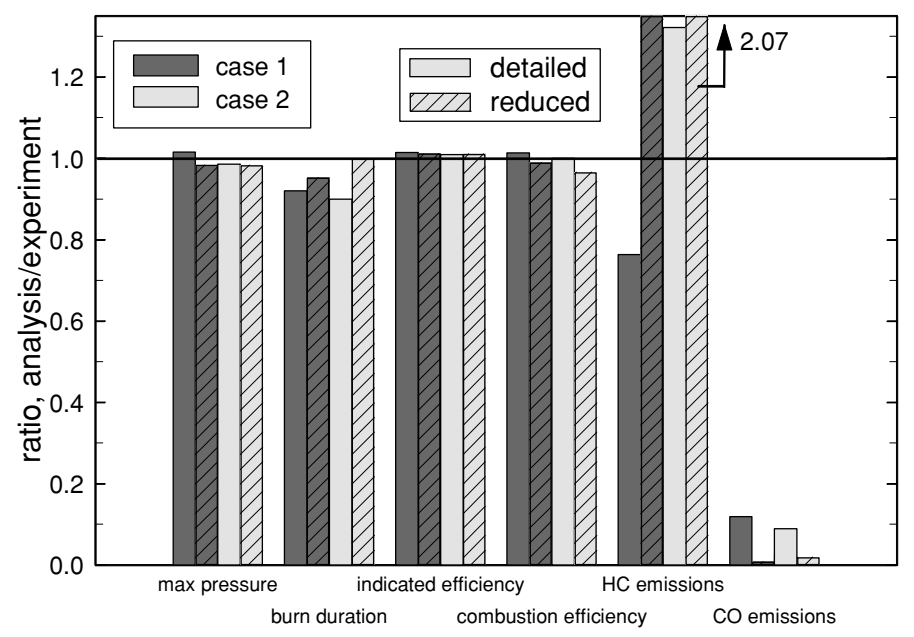

Figure 5. Comparison between experimental and numerical results for the main combustion parameters of $\mathrm{HCCl}$, for the two cases being analyzed. The figure shows two numerical results for each experimental result, corresponding to the reduced and the detailed chemical kinetic mechanisms.

\section{CONCLUSION}

A reduced chemical kinetics mechanism for iso-octane has been derived from a detailed mechanism by eliminating unimportant reaction steps and species. The reduced mechanism has been developed for conditions typical of $\mathrm{HCCl}$ combustion. The reduced mechanism contains 199 species and 383 reactions, while the original detailed mechanism contains 859 species and 3606 reactions.

The reduced mechanism has been applied to a multizone analysis of iso-octane $\mathrm{HCCl}$ combustion by using a sequential methodology previously demonstrated by the authors. The multi-zone analysis takes into account the temperature distribution that exists inside the combustion chamber and has been used in the past to obtain accurate predictions of $\mathrm{HCCl}$ combustion and emissions. The main conclusions of this work are as follows. 
The reduced chemical kinetic mechanism does an excellent job predicting pressure traces and heat release rates. Pressure traces and heat release rates obtained with the reduced mechanism are comparable to (and in some cases better than) the results obtained with the detailed mechanism.

The detailed mechanism generates better predictions for $\mathrm{HCCl}$ emissions than the reduced mechanism. The reduced mechanism considerably overpredicts hydrocarbon emissions (by as much as a factor of 2 in one case). Carbon monoxide is underpredicted in all cases. The detailed mechanism underpredicts $\mathrm{CO}$ emissions by an order of magnitude, while the reduced mechanism underpredicts $\mathrm{CO}$ emissions by as much as 2 orders of magnitude. It is considered that this underprediction occurs because the reduced mechanism was targeted for predicting $\mathrm{HCCl}$ ignition, and not $\mathrm{CO}$ emissions. In addition to this, previous work by the authors has shown that $\mathrm{CO}$ emissions are intrinsically difficult to predict.

The reduced mechanism yields accurate results for $\mathrm{HCCl}$ combustion while reducing by a factor of 20 the computational time required to run a 10-zone problem with iso-octane fuel. The reduced model is therefore a very useful tool for sensitivity studies and optimization analyses that require multiple executions of the code.

\section{NOMENCLATURE}

$\bar{C}_{k i}^{P}=$ normalized production rate of k-th species in i-th reaction step;

$\bar{C}_{k i}^{d}=$ normalized destruction rate of $\mathrm{k}$-th species in i-th reaction step;

$\mathrm{I}=$ total number of reaction steps;

$\mathrm{q}_{\mathrm{i}}=$ rate of progress variable for $\mathrm{i}$-th reaction step;

$\mathrm{T}=$ temperature;

$X_{k}=$ mole fraction of $k$-th species;

$\alpha, \alpha_{i}=A$-factor in Arrhenius expression of $\mathrm{i}$-th reaction step;

$\beta, \beta_{\mathrm{i}}=$ temperature exponent in Arrhenius expression of $\mathrm{i}-$ th reaction step;

$v_{\mathrm{ki}}=$ stoichiometric coefficient of $\mathrm{k}$-th species in i-th reaction step;

\section{ACKNOWLEDGMENTS}

This project is funded by DOE, Office of Transportation Technologies, Steve Goguen and Gurpreet Singh, program managers. Work performed under the auspices of the U.S. Department of Energy by University of
California Lawrence Livermore National Laboratory under Contract W-7405-ENG-48.

\section{REFERENCES}

1. Lam, S.H., "Using CSP to Understand Complex Chemical Kinetics," Combustion Science and Technology, vol. 89, pp. 375-404, 1993.

2. Mass, U. and Pope, S.B. "Simplifying Chemical Kinetics- Intrinsic Low Dimensional Manifolds in Composition Space," Combustion and Flame, vol. 88, pp.239-264, 1992.

3. Frenlack, M. "Reduction of Chemical Reaction Models," in "Numerical Approaches to Combustion Modeling," Edited by Oran, E.S. and Boris, J.P., Progress in Astronautics and Aeronautics, vol. 135. AIAA, 1991.

4. Griffiths, J.F., "Reduced Kinetic Model and Their Application to Practical Combustion Systems," Progress in Energy and Combustion Science, vol. 21, pp. 25-107, 1995.

5. Soyhan, H.S., Lovas, T., and Mauss, F., "A Stochastic Simulation of an $\mathrm{HCCl}$ Engine using Automatically Reduced Mechanism," ASME 2001 ICE Fall Technical Conference, Vol. 37-2, paper no. 2001-ICE-416, 2001.

6. Lovas, T., Amneus, P., Mass, F. and Mastorakes, E., "Comparison of Automatic Reduction Procedures for Ignition Chemistry," 29-th Symposium on Combustion, Sapporo, Japan, July 21-26, paper 2B10, 2002.

7. Suzuki, H., Koike, N., Ishii, H., and Odaka, M., "Exhaust Purification of Diesel Engines by Homogeneous Charge with Compression Ignition Part 1: Experimental Investigation of Combustion and Exhaust Emission Behavior Under Pre-Mixed Homogeneous Charge Compression Ignition Method," SAE paper 970313, 1997.

8. Najt, P. M. and Foster, D. E., "Compression-Ignited Homogeneous Charge Combustion," SAE paper 830264, 1983.

9. Noguchi, M., Tanaka, Y., Tanaka, T., and Takeuchi, Y., "A Study on Gasoline Engine Combustion by Observation of Intermediate Reactive Products During Combustion," SAE paper 790840, 1979.

10. lida, N., "Alternative Fuels and Homogeneous Charge Compression Ignition Combustion Technology," SAE paper 972071, 1997.

11. Aceves, S. M., Flowers, D.L., Westbrook, C.K., Smith, J. R., Pitz, W.J., Dibble, R., Christensen, M. and Johansson, B., "A Multi-Zone Model for Prediction of $\mathrm{HCCl}$ Combustion and Emissions," SAE Paper 2000-01-0327, 2000.

12. Aceves, S.M., Flowers, D.L., Martinez-Frias, J., Smith, J.R., Westbrook, C., Pitz, W., Dibble, R., Wright, J., Akinyemi, W.C., and Hessel, R.P., "A Sequential Fluid-Mechanic Chemical-Kinetic Model of Propane HCCl Combustion," SAE Paper 2001-011027. 
13. Aceves, S.M., Martinez-Frias, J., Flowers, D.L., Smith, Dibble, R.W., Wright, J.F., and Hessel, R.P., "A Decoupled Model of Detailed Fluid Mechanics Followed by Detailed Chemical Kinetics for Prediction of Iso-Octane HCCl Combustion," SAE Paper 2001-01-3612, 2001.

14. Amsden, A.A., "KIVA-3V: A Block-Structured KIVA Program for Engines with Vertical or Canted Valves," Los Alamos National Laboratory Report LA-13313MS, 1997.

15. Lund, C. M., "HCT - A General Computer Program for Calculating Time-Dependent Phenomena Involving One-Dimensional Hydrodynamics, Transport, and Detailed Chemical Kinetics," Lawrence Livermore National Laboratory report UCRL-52504, 1978.
16. Goyal, P., "Development of Skeletal Chemistry Mechanisms for Combustion Modeling- A Study of Current Methods," M.S. Thesis, University of California at Berkeley, May 2002.

17. Curran, H. J., Gaffuri, P., Pitz, W. J., Westbrook, C. K., and Leppard, W. R., "Autoignition Chemistry of the Hexane Isomers: An Experimental and Kinetic Modeling Study," SAE paper 952406, 1995.

18. Heywood, J. B., Internal Combustion Engine Fundamentals, McGraw-Hill, Inc., New York, NY, 1988.

19. Flowers, D.L., Aceves, S.M., Martinez-Frias, J., Dibble, R.W., "Prediction of Carbon Monoxide and Hydrocarbon Emissions in Isooctane $\mathrm{HCCl}$ Engine Combustion Using Multi-Zone Simulations," Proceedings of the Combustion Institute, 2002. 